\title{
POLÍTICAS SOCIAIS, EDUCAÇÃO E DESENVOLVIMENTO ECONÔMICO: BUSCA POR EVIDÊNCIAS CORRELACIONAIS A PARTIR DAS AVALIAÇÕES DO IDEB DE TRÊS MUNICÍPIOS PAULISTAS FOR CORRELATED EVIDENCES FROM THE ASSESSMENTS OF IDEB IN THREE MUNICIPALITIES OF SÃO PAULO
}

\section{Maria Helena Scalabrin Cardoso Gomes}

Doutora em Administração pela Universidade Municipal de São Caetano do Sul (USCS), São Caetano do Sul (SP), Brasil

\section{Luis Paulo Bresciani}

Professor doutor da Universidade Municipal de São Caetano do Sul (USCS), São Caetano do Sul (SP), Brasil

\section{Wilson Aparecido Amorim}

Doutor em Políticas Sociais e do Trabalho pela Universidade de São Paulo (USP), São Paulo (SP), Brasil
Data de recebimento: 08-04-2014

Data de aceite: 22-10-2015

\section{RESUMO}

Este trabalho teve como objetivo estudar as políticas de desenvolvimento social de três municípios paulistas: Americana, Cajuru e São Caetano do Sul, a partir de indicadores sociais e econômicos, conjugando-os com os resultados educacionais. A partir de referenciais teóricos, pesquisas de campo, dados coletados no IBGE, Fundação Seade e avaliações do Ministério da Educação, EducaCenso/ldeb, nos anos de 2007, 2009, 2011 e 2013 formou-se um quadro conceitual cujos resultados revelaram que índices de riqueza e de desenvolvimento não estão diretamente correlacionados ao desempenho da educação pública local, assim como escola de tempo integral não é por si só representante de melhor qualidade de ensino. Um modelo de gestão voltado para a qualidade do ensino trouxe indícios de ser um aspecto central nos resultados da educação.

Palavras-chave: Políticas sociais; educação; desenvolvimento econômico; equidade social.

\section{ABSTRACT}

This paper aimed to study the social development policies of three municipalities of the state of São Paulo: Americana, Cajurú and São Caetano do Sul, from social and economic indicators, combining them with educational outcomes. From the theoretical frameworks, field researches, data collected from IBGE, Seade Foundation and the evaluations of Education Ministry, EducaCenso/Ideb, in 2007, 2009, 2011 and 2013, a conceptual framework could be prepared, whose results reveal that the indices of wealth and development are not directly correlated with the performance of local public education, as well as full time school does not represent better education quality. A management model focused on education quality brought evidence of being a central aspect to the results of education.

Keywords: Social policies; education; economic development; social equity. 


\section{INTRODUÇÃO}

Como "fato social total", a educação abrange todas as realidades do desenvolvimento humano; é considerada como um dos fatores essenciais para a melhoria de vida das pessoas e do progresso das nações, por mais diferentes que sejam os seus índices materiais e espirituais de existência. No Brasil, políticas educacionais têm sido implementadas, em escala ascendente nas últimas décadas, tendo em vista os problemas graves detectados nos diferentes níveis de escolaridade, a refletir as imensas desigualdades sociais dos brasileiros. Políticas educacionais e planejamentos sucedem-se nas áreas federais, estaduais e municipais.

Tendo em vista tal aspecto, este artigo analisa o alcance de planos e propostas de três cidades paulistas: São Caetano do Sul, que está entre os municípios mais ricos do Estado, Americana, que está em uma posição intermediária entre São Caetano do Sul, e o município de Cajuru, este último o menos economicamente desenvolvido entre os três. O município de Cajuru foi eleito como contraposição aos dois primeiros porque, a despeito dos baixos índices de desenvolvimento econômico, possui também alta vulnerabilidade social nos entornos dos equipamentos públicos de onde provém a demanda e, apesar desse fato, tem um ensino de alta qualidade, conforme o Índice de Desenvolvimento da Educação Básica (Ideb), estando entre os primeiros colocados do Estado de São Paulo e do Brasil. As pesquisas ocorreram em 2007, 2009, 2011 e 2013. O Ideb 2013 não se encontra aqui incluído pelo fato de não ter sido divulgado no momento da conclusão deste trabalho. Procurou-se pelas evidências dos elementos considerados eficientes e eficazes do sistema educacional do nível básico - eixo estruturante para os níveis posteriores e decisivos do progresso econômico, social e cultural dos que dele partilharam.

\section{REFERENCIAIS TEÓRICOS}

Os marcos teóricos deste artigo são plurais. O entendimento de que a lógica mercantil e a lógica produtiva moderna não substituem as antigas formas de constituição dos vínculos e alianças entre os seres humanos - expressos, entre outros por Marcel Mauss (apud LÉVI-STRAUSS, 1974; MARTINS, 2005) - é importante para entender como uma concepção, com essa abrangência, impacta no cotidiano de cada indivíduo.

Concebida como um fato social total, a educação traz uma compreensão dos fenômenos de natureza econômica, cultural, política e social, que compõem a sociedade. Nessa perspectiva, importa conhecer o sentido de ações modernizadoras, porém sem deixar de incluir as raízes históricas, quer da localidade, quer dos indivíduos que foram chegando e incorporando-se a ela. O ethos social, unido à ideia de habitus, proposta por Pierre Bourdieu (1983), constitui mais um marco a conferir legitimidade a esta análise. Complementa a revisão teórica, Comte (1988), Dewey (1971), Kuenzer (1985), Darcy Ribeiro (1986), Sonia Draibe (2001), Calmon (2002), Birkland (2003), Saviani (2008) Schartzman e Cox (2009), entre outros. Dados empíricos de confiabilidade estatística, confrontados em metodologia comparativa, embasaram os marcos teóricos. O significado e a definição de "políticas públicas" inserem-se no primeiro marco, procurando entender o problema de investigação, isto é, a avaliação dos impactos possíveis de suas formulações as suas implementações nos sistemas de ensino, em campos de estudo com contornos bem definidos.

Segundo Calmon (2002), atribuiu-se à imperatriz Maria Teresa da Áustria, a frase: "a educação é e sempre foi, em cada época, um fato político". Considerando essa premissa correta, devem-se considerar os impactos dos atos políticos na vida das pessoas, intrinsecamente conectados aos meios de sobrevivência, atrelados ao seu tempo e a 
sua história. A educação vem como forma de iluminar os espíritos, mas também de proporcionar condições dignas de sobrevivência constitucionalmente garantidas como "desenvolvimento pleno" (BRASIL, 1988).

\section{METODOLOGIA E DELINEAMENTO DA PESQUISA}

A questão levantada neste estudo teve como marco referencial as avaliações do IDEB. Buscou-se por evidências se os resultados da educação básica guardavam proporcionalidade ao desenvolvimento econômico e social dos municípios estudados, cuidando para encontrar contraposições ou justaposições nas questões de análise de modo a compor um quadro referencial. O método escolhido para as pesquisas de campo foi a pesquisa exploratória, por proporcionar maior familiaridade com o problema, tornando-o mais explícito (GIL, 2010). Pode ser também classificada como descritiva, uma vez que expõe características de determinada população ou de determinado fenômeno. Procurou-se estudar as questões epistemológicas relacionadas ao ato educativo que dessem fundamento teórico para preparação para as entrevistas de campo e de análise às questões de cenário nas quais se inseriam as escolas públicas municipais. Para essa finalidade foi efetuada a revisão e associação de literatura antes da coleta das opiniões dos gestores, docentes e pais ou cuidadores em relação à percepção de cada um desses atores com relação à oferta e demanda. As pesquisas secundárias foram obtidas no IBGE, Fundação Seade e EducaCenso/ldeb nos anos 2007, 2009 e 2011 e 2013. Buscou-se identificar quais eram os fatores comuns e perceptíveis na qualidade obtida no ensino público dos municípios pesquisados, as distintas ofertas de serviços e soluções e como essas se inter-relacionavam e se amalgamavam ou não na gestão municipal.

\section{POLÍTICAS PÚBLICAS: PROPOSIÇÕES, SIGNIFICADOS E NOMENCLATURA}

O termo "política" tem uma extensa gama de significados, pode ser concebido como doutrina do direito e da moral, teoria do Estado, a arte ou a ciência de governar (ABBAGNANO, 2000). As concepções dos séculos XVIII e XIX oscilam entre uma postura considerada romântica e o cientificismo incipiente. Hegel declarou que, por ser o Estado uma substância concreta, é com base nela que deve ser pautado o princípio de sua ação, uma vez que ele é a manifestação jurídica da nação (HEIDEMANN, 2009). Comte situa as políticas nas ciências sociológicas e trata do tema no Sistema de política positiva (1988), considerando que os fenômenos políticos sujeitam-se a leis invariáveis, cujo uso pode permitir e influenciar esses mesmos fenômenos. Marx concebe criticamente que o público e o privado têm íntima conexão. Para ele, as relações jurídicas e as formas de Estado não podem ser compreendidas por si sós, nem pela evolução humana, que está condicionada por raízes oriundas das relações materiais da existência, sofrendo, portanto, os seus condicionamentos.

Mesmo com os embates críticos do século XIX - o espiritualismo de Hegel, o materialismo de Marx ou o positivismo de Comte - a inserção do indivíduo na sociedade era otimista, pois visava a um progresso rumo a uma sociedade não conflitual, em um horizonte de médio e longo prazo, baseada na promoção humana. Essa posição foi seriamente abalada pela ocorrência da Grande Guerra, que de certa forma, anestesiou essas idealizações, colocando os finalismos filosóficos do "fim da História" (PERRY, 1992) no banco dos réus, de onde saíram condenados. As teorias subsistiram, mas não as suas previsões.

É conveniente trazer para o debate, o termo comumente utilizado "políticas públicas". Ao substantivo política foi agregado o adjetivo público. A expressão em inglês, public policy, leva 
em conta, na junção dos termos, o sentido daquilo a que se refere a organização da vida coletiva, os processos (policies). A tradução redundante do termo já foi assinalada por Birkland (2001). A falta de consenso sobre o significado da expressão parte da própria tradução de public policy para políticas públicas, pode, segundo o autor, constituir-se em um pleonasmo. De acordo com o Houaiss (2001), "política" deriva-se de "polis", "cidade". "Polis", por sua vez, tem algumas acepções importantes, variando desde aglomeração humana, cidadela, até Estado. A raiz deste termo é "П $\lambda \alpha$ " (Pla), que significa "encher", o que explica o sentido primeiro de "aglomeração" (LIDELL; SCOTT 1968; BAILLY, 1969). Os dicionários ingleses (LANDAU et al., 1988; SWAN, 2000) esclarecem por que policy diverge do sentido de politics. Quem primeiramente traduziu o primeiro termo para o português viu-se em grande dificuldade, dado que o cognato equivalente seria "polícia". A razão de tal escolha é simples. Policy chegou à língua inglesa pelo francês.

No histórico da língua francesa, police admite três acepções, que acabam por relatar as transformações de seu significado. Em princípio compreendeu-se como organização política e administrativa de uma sociedade, de um Estado. Depois, passou a ser entendida como uma organização racional da ordem pública em um grupo social, uma regulamentação. Por último, evoluiu para o significado de um conjunto de órgãos e de instituição da força pública, encarregados de assegurar a manutenção da ordem, impedindo que infrações fossem cometidas, e, quando cometidas, reprimi-las.

A cultura inglesa, portanto, justifica o emprego do termo "público" para esclarecer o termo "política". Em português, a redundância passou despercebida, mas é preciso enfatizar que "política", por sua própria natureza, é necessariamente pública. Fora do campo etimológico, a expressão "política pública" significa um modelo de escolha política, legitimado pela sociedade, ou do acatamento do modelo imposto pelos governantes aos sujeitos sociais. Bem-estar, desenvolvimento econômico e social - estes mais comumente tratados nas literaturas - partem de muitos conceitos e atribuições.

Heidemann (2009) conceitua políticas públicas ligadas ao progresso e ao ideal de desenvolvimento. Desenvolvimento tem o significado de implantar uma economia de mercado, que possa incluir a maior parte de seus cidadãos. O Estado é um agente unitário que atua em prol dos interesses de um corpo coletivo, interligando a ideia de desenvolvimento e progresso, assim como as políticas públicas destinadas a esse fim. A formulação de políticas públicas tem início quando um conjunto proposições vai ao encontro das mudanças esperadas pela sociedade. Os esquemas em que se agrupam várias atividades e vêm a se constituir como um conjunto de processos políticos e gerenciais deveriam obrigatoriamente seguir o esquema: identificação de problemas, organização de agenda, formulação, legitimação, implementação e avaliação. Em uma linha espaço-tempo-abrangência, as novas formulações partem não somente de um modelo a ser construído, mas de uma análise do que já foi feito, pois a herança recebida determina a capacidade de realizações no presente que, por sua vez, determina o que será herdado no futuro. Assim, as formulações de políticas sociais das suas proposições à sua implementação, e avaliação - devem ter um cronograma bem planejado.

Draibe (2001) estuda as políticas sociais brasileiras e analisa alguns dos programas sociais implantados. Inúmeros fatores que podem ser atribuídos a sua baixa efetividade, destacando-se a ausência de uma porta de saída para aqueles que são assistidos por eles. Draibe enfatiza que não há por parte dos governos federais, estaduais e municipais uma vontade política de resolver a questão, pois muitas vezes essas iniciativas são usadas como propaganda de um determinado governo, sem a preocupação com a diminuição da desigualdade social e melhoria na distribuição de renda. Para a autora, 
deve haver uma maior efetividade do ato social, em um sistema que compreenda um conjunto de processos e subprocessos de implementação: gerenciamento e decisão; divulgação e informação; seleção de agentes implementadores e beneficiários; capacitação; logística e operacionalidade da atividade fim; fontes de financiamentos e gastos; provisão de recursos materiais; e, por fim, processos de monitoramento e de avaliação, pois somente registrar percentuais, metas físicas e financeiras não significam avaliação de um programa.

A Comissão Econômica para a América Latina e o Caribe (CEPAL) examinou as políticas públicas de desenvolvimento e emitiu um documento intitulado $\boldsymbol{A}$ hora da igualdade: brechas por fechar, caminhos para abrir (2010), no qual admite o peso estratégico do Estado na busca de soluções para problemas de desigualdade e bem-estar social. Considera que a assistência social, a saúde e a educação são geradores de padrões progressivos de distribuição de renda. A CEPAL esclarece que a competitividade fundamentada em capacidades humanas e, com inserção produtiva, obtém maiores receitas no crescimento sustentado em longo prazo. O texto ainda faz referência à igualdade de acesso à educação e sua direta relação com as condições de empregabilidade, considerando a industrialização como o único caminho para a superação do subdesenvolvimento. O termo "desenvolvimento" entrou no fundamento das políticas públicas, abrangendo conceitos situados além da economia, tais como, as dimensões de promoção humana e social.

\subsection{As políticas educacionais como fator de sustentação do desenvolvimento humano, econômico e social}

A Constituição de 1988 abriu um grande leque de direitos individuais e coletivos (FÁVERO, 1996). Para o exercício desses direitos, apresentou-se como necessária a transformação da realidade social e econômica, fato que fez que o Estado se legitimasse a fim de realizar programas e ações públicas visando à concretização dos objetivos de relevância econômica e social voltados ao desenvolvimento. A materialidade dos direitos fundamentais, entre eles o direito subjetivo à educação, vem como efetividade da cidadania, desenvolvimento pleno, inclusão social e formação de mão de obra. Cabe aqui pontuar é a distinção que a Constituição de 1988 faz para a promoção do desenvolvimento, partindo de duas significações: crescimento econômico e crescimento social. O artigo 205 considera a educação "como direito de todos, dever do Estado e da família, promovida e incentivada pela sociedade, visando ao pleno desenvolvimento da pessoa, seu preparo para o exercício da cidadania e qualificação para o trabalho". Em outros artigos, a Carta Magna reforça esse direito social subjetivo, com condições de acesso e permanência na escola e igualdade de oportunidades: artigos $6^{\circ}$; 205; 206; 208.

Com Fernando Henrique Cardoso, na Presidência da República em seu primeiro mandato (1995-1998), houve a Reforma do Estado, confiada ao Ministro Bresser Pereira. Essa reforma objetivou o fortalecimento da democracia participativa pela criação de instrumentos de inserção popular, nas tomadas de decisão, por meio de conselhos gestores e fóruns sociais, para aproximar o Estado da sociedade civil, e visando a aumentar a sua eficiência pela fiscalização e controle de suas ações (BRESSER, 1997). No bojo dessas medidas, vieram as reformas educacionais, que, na época, tiveram por foco o Ensino Fundamental, considerado urgente e necessário para a equidade social. Em 1996, foi promulgada a Lei de Diretrizes e Bases da Educação Brasileira nº 9394 com um traço estrutural nos propósitos da educação básica, ratificando as quatro fundamentações do direito subjetivo da educação: pleno desenvolvimento humano; preparo para o exercício da cidadania; preparo para o mundo do trabalho e ingresso nos 
níveis ulteriores do ensino. O primeiro movimento do Executivo, entretanto, em prol da educação básica foi ampliar e garantir o acesso universal aos sistemas de ensino, e o segundo, investir na sua qualidade (BRASIL, 1993).

As políticas educacionais orientam para um ensino que não marche paralelamente ao mercado, mas que forneça respostas às demandas sociais. Assim, incentivaram-se programas de formação técnica e profissional. A esse respeito, Acácia Kuenzer já em 1985 fazia ressalvas ao considerar a educação profissional brasileira, "anacrônica e confusa", não servindo nem ao capital. É crítica correta, mas talvez extremada, pois há de se considerar a formação dos indivíduos para a inserção no mercado de trabalho, cada vez mais demandando conhecimentos e habilidades práticas. Todavia, na história da educação nacional, observam-se experiências inovadoras, e de sucesso onde foi implantada, que até nos dias atuais servem de referências: os ginásios vocacionais no Estado de São Paulo, abortado logo no início do regime militar, perdendo-se uma proposta que conectava escola à vida (JACOBUCCI, 2002).

\subsection{Os planos nacionais de educação: decênios 2001/2010 e 2011/2020}

O primeiro Plano Nacional de Educação (PNE, 2001-2010), baseado nos erros e acertos do Plano Decenal, promoveu significantes alterações, a começar pelas diretrizes, alinhadas ao conceito de "estado mínimo": descentralização administrativa e financeira; priorização do Ensino Fundamental; divisão da responsabilidade com a educação; e municipalização do Ensino Fundamental. A atribuição aos estados e municípios da responsabilidade sobre a Educação Básica trouxe aspectos positivos e negativos. Os negativos situam-se na desobrigação da União e na transitoriedade do poder político local, estabelecendo processos de rupturas ou prorrogação de políticas educacionais inadequadas.
Os positivos se dão pela proximidade de oferecer os serviços a quem é deles beneficiário, exercendo mais proximamente os mecanismos de controle e de fiscalização. A proposta de elaboração do PNE encontrou abrigo no artigo 214 da Constituição de 1988, que expressa como objetivos nacionais a erradicação do analfabetismo, a universalização do atendimento escolar, a melhoria da qualidade do ensino, a formação para o trabalho e a promoção humanística, científica e tecnológica do País. Ressalte-se que a construção de planos nacionais de educação tem demanda histórica, já estava presente no Manifesto dos Pioneiros da Educação, de 1932, ao tratar da necessidade de um plano amplo e utilitário para toda a Nação (SAVIANI, 2008).

Educação de qualidade exige investimentos. Nas últimas décadas esses foram escassos. Em 2008, foram aplicados 4,7\% do Produto Interno Bruto. A proposta declarada do governo Luiz Inácio da Silva era, ao final de seu mandato, chegar a 6\%. As informações do Ministério da Educação (MEC) apontam um investimento atual de $5 \%$. Nas metas preconizadas pelo PNE (2001-2011) estavam: aprimorar o Fundo de Desenvolvimento da Educação Básica (Fundeb), monitorar os planos no âmbito do Executivo; revisar e atualizar as metas; monitorar a qualidade do ensino em todo território nacional; divulgar resultados; estabelecer programas para a erradicação do analfabetismo - que, de certa forma, foram cumpridas (CALLEGARI, 2009). Em que se pesem os prós e os contras da avaliação do PNE, é preciso concordar que, hoje, as informações estão mais ao alcance da sociedade do que há dez anos, assim como os mecanismos de participação social e de gestão pública.

O PNE para o decênio 2011/2020 teve uma estrutura mais enxuta, com metas mais específicas. Partiu de uma consulta às bases educativas com encontros com interessados e profissionais do ensino e fechando um diagnóstico, 20 metas foram desenhadas para a melhoria da educação. O Plano estabelecia inicialmente um investimento gradativo na educação, mas os educadores e movimentos sociais 
pleiteavam 10\%. Esse Plano foi sancionado somente em 2015, depois de inúmeros debates na Câmara e no Senado Federal, ficando aprovada a destinação de $75 \%$ dos royalties do petróleo e $50 \%$ do Fundo Social do Pré-Sal para educação e mantendo o investimento progressivo até $10 \%$ do PIB nacional.

\subsection{Plano de Desenvolvimento da Educação (PDE)}

Em movimento gerencial, o MEC chegou às salas de aula. Essa política educacional de controle começou a dar efeito e ser motivo de preocupação para os gestores públicos. Os munícipes ficaram atentos, organizando-se e constituindo mecanismos de controle e gestão participativa - pressão direta - ficando os dirigentes locais expostos pela proximidade e, portanto, sensíveis a ela. O plano enfatizava a responsabilização/ fiscalização, accountability, além de declarar, como um dos objetivos, sair da fragmentação dos planos e das propostas anteriores, buscando a sistematização e a integração dos processos na área educacional.
Esse modelo gerenciador, em que pesem as posições críticas ao modelo pelos educadores, trouxe uma alteração positiva na metodologia da avaliação da educação básica, ao redefinir os critérios avaliadores, estabelecer metas para cada município.

\subsection{PDE: estabelecimento de metas}

As metas estabelecidas pelo MEC até 2020 é chegar ao índice 6,0 para séries iniciais e 5,5 nas séries finais do Ensino Fundamental. Analisando os resultados (médias) obtidos pelos estados da Federação nas últimas avaliações, muitos estados, caso mantenham os resultados apresentados nas últimas avaliações, possivelmente não atingirão as metas previstas. Na Tabela 1 podem ser visualizadas as médias de cada estado nas séries iniciais e finais. Um dado relevante e necessário acrescentar na análise é que as primeiras séries do Ensino Fundamental, via de regra, obtêm resultados mais elevados, em grande parte resultante da qualidade da educação infantil, ou seja, as condições de acesso dos educandos nesse nível educacional.

Tabela 1 - Índice médio das escolas públicas nas séries iniciais (SI) e séries finais (SF) por estados da Federação, Brasil

\begin{tabular}{|c|c|c|c|c|c|c|c|c|c|c|c|c|c|c|c|c|c|}
\hline \multirow{2}{*}{ 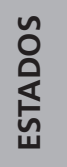 } & \multicolumn{2}{|c|}{2007} & \multicolumn{2}{|c|}{2009} & \multicolumn{2}{|c|}{2011} & \multicolumn{2}{|c|}{2013} & \multirow{2}{*}{ 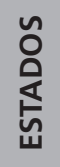 } & \multicolumn{2}{|c|}{2007} & \multicolumn{2}{|c|}{2009} & \multicolumn{2}{|c|}{2011} & \multicolumn{2}{|c|}{2013} \\
\hline & SI & SF & SI & SF & SI & SF & SI & SF & & SI & SF & SI & SF & SI & SF & SI & SF \\
\hline$A C$ & 3,7 & 3,7 & 4,2 & 4,1 & 4,5 & 4,1 & 5,0 & 4,3 & PA & 3,0 & 3,1 & 3,6 & 3,4 & 4,0 & 3,5 & 3,8 & 3,4 \\
\hline $\mathrm{AL}$ & 3,1 & 2,8 & 3,4 & 2,7 & 3,5 & 2,6 & 3,7 & 2,8 & PB & 3,3 & 2,8 & 3,6 & 2,9 & 4,0 & 3,1 & 4,2 & 3,2 \\
\hline AM & 3,4 & 3,2 & 3,8 & 3,4 & 4,2 & 3,7 & 4,5 & 3,8 & $\mathrm{PE}$ & 3,3 & 2,6 & 3,7 & 3,0 & 3,9 & 3,2 & 4,1 & 3,4 \\
\hline AP & 3,3 & 3,4 & 3,8 & 3,6 & 4 & 3,5 & 3,9 & 3,4 & PI & 3,3 & 3,2 & 3,8 & 3,5 & 4,1 & 3,6 & 4,1 & 3,6 \\
\hline BA & 3,2 & 2,8 & 3,5 & 2,9 & 3,9 & 3,1 & 3,0 & 3,2 & PR & 4,8 & 4,0 & 5,3 & 4,1 & 5,4 & 4,1 & 5,8 & 4,1 \\
\hline $\mathrm{CE}$ & 3,5 & 3,3 & 4,1 & 3,6 & 4,7 & 3,9 & 5,0 & 4 & RJ & 4,1 & 3,5 & 4,4 & 3,4 & 4,8 & 3,7 & 4,9 & 3,9 \\
\hline DF & 4,8 & 3,5 & 5,4 & 3,9 & 5,4 & 3,9 & 5,6 & 3,9 & RN & 3,2 & 2,8 & 3,5 & 2,9 & 3,8 & 3,0 & 4,0 & 3,2 \\
\hline ES & 4,3 & 3,7 & 4,8 & 3,8 & 5,0 & 3,9 & 5,2 & 3,9 & RO & 3,9 & 3,3 & 4,3 & 3,5 & 4,6 & 3,6 & 5,1 & 3,8 \\
\hline GO & 4,1 & 3,5 & 4,7 & 3,7 & 5,1 & 3,9 & 5,5 & 4,5 & RR & 4,1 & 3,5 & 4,2 & 3,7 & 4,5 & 3,6 & 4,8 & 3,5 \\
\hline MA & 3,5 & 3,2 & 3,7 & 3,4 & 3,9 & 3,4 & 3,8 & 3,4 & RS & 4,5 & 3,7 & 4,7 & 3,9 & 5,1 & 3,9 & 5,4 & 4,0 \\
\hline MG & 4,6 & 3,8 & 5,5 & 4,1 & 5,8 & 4,4 & 5,9 & 4,6 & SC & 4,7 & 4,1 & 5,1 & 4,3 & 5,7 & 4,7 & 5,9 & 4,3 \\
\hline MS & 4,1 & 3,7 & 4,5 & 3,9 & 5,0 & 3,8 & 5,0 & 3,9 & SE & 3,2 & 2,8 & 3,4 & 2,8 & 3,6 & 2,9 & 3,8 & 2,8 \\
\hline MT & 4,3 & 3,7 & 4,8 & 4,2 & 4,9 & 4,3 & 5,2 & 4,2 & SP & 4,8 & 4,0 & 5,3 & 4,3 & 5,4 & 4,4 & 5,8 & 4,4 \\
\hline & & & & & & & & & TO & 4 & 3,6 & 4,4 & 3,9 & 4,0 & 4,8 & 5,0 & 3,8 \\
\hline
\end{tabular}

Fonte: Elaborado pelos autores com base em MEC; Ideb (2007, 2009, 2011, 2013). 
Conforme a tabela anterior, em 2013 os estados com os melhores índices nas séries iniciais foram: Minas Gerais, Santa Catarina e São Paulo. Nas séries finais, os melhores resultados concentraram-se em Minas Gerais (4,6), Goiás $(4,5)$ e São Paulo $(4,4)$. Minas Gerais e Goiás superaram as metas previstas pelo Ideb: 4,4 e 4,1 respectivamente. O estado de São Paulo ficou abaixo da meta prevista: 4,7.

Os resultados mais críticos nas séries finais do Ensino Fundamental estão em Alagoas $(2,8)$ e Sergipe $(2,8)$. Um aspecto que fica em aberto nesta pesquisa, e indicadora de futuros estudos, é a condição de entrada e saída do alunado nas séries iniciais e nas séries finais, conforme já apontado. As maiores diferenças estão em: Paraná $(1,7)$; Santa Catarina $(1,6)$; Rio Grande do Sul $(1,4)$ e São Paulo $(1,4)$.

\subsection{Recorte de estudo: avaliação do resultado educacional de três municípios paulistas}

Partindo de uma investigação do desempenho das escolas públicas e as diferenças evidenciadas entre desenvolvimento econômico, social e educacional, elegeu-se como pesquisa empírica os municípios paulistas de Americana, Cajuru e São Caetano do Sul.

A escolha desses três municípios deveu-se aos quesitos: Cajuru foi o município que se destacou pela melhor qualidade do ensino (primeiro lugar no ranking estadual e nacional segundo o Ideb) e de mais baixa renda entre os três pesquisados.
Americana situa-se no nível de desenvolvimento econômico intermediário entre os três municípios e possui cinco escolas municipais em tempo integral (CIEPs) nos modelos propostos por Leonel Brizola e Darcy Ribeiro. São Caetano do Sul tem índices de desenvolvimento humano e econômico mais elevados no Brasil, e resultados educacionais inferiores aos dois municípios citados, embora tenha erradicado o analfabetismo.

\subsection{Economia, desenvolvimento humano, social e educacional}

Para compreensão de um fato social, é necessário conhecer o contexto geral onde ocorre a manifestação de uma determinada situação ou problema: investigação das ações, percepções, comportamentos e suas interações devem ser relacionados ao fato estudado para uma melhor compreensão da natureza do objeto estudado (LÉVI-STRAUSS, 1974). O estudo de um município com essa dimensão revela o que a sociedade faz de si mesma.

Observa-se que os três municípios estudados possuem características diversas entre si no que se refere à geografia, formação histórica e econômica. Conforme a Tabela 1, São Caetano do Sul destaca-se pelo desenvolvimento econômico e humano. Americana, por ter uma grande parte de sua demanda atendida por escolas de tempo integral, e Cajuru por se destacar no ranking oficial das melhores escolas do Estado e do Brasil com elevados resultados na qualidade de seu ensino público, tomando-se por referência o Ideb.

Tabela 2 - Índices econômicos, desenvolvimento humano e educacional

\begin{tabular}{|c|c|c|c|c|c|c|c|c|c|c|}
\hline \multirow{2}{*}{ Município } & \multirow{2}{*}{$\begin{array}{l}\text { PIB/Milhões } \\
\text { (RS) } 2010\end{array}$} & \multirow{2}{*}{$\begin{array}{l}\text { PIB per Capita, } \\
2010\end{array}$} & \multirow{2}{*}{$\begin{array}{l}\text { Rendimento médio } \\
\text { (vê*) } 2011\end{array}$} & \multirow{2}{*}{$\begin{array}{c}\text { IDH-M } \\
2010\end{array}$} & \multicolumn{2}{|c|}{ Ideb 2009} & \multicolumn{2}{|c|}{ Ibeb 2011} & \multicolumn{2}{|c|}{ Ibeb 2013} \\
\hline & & & & & SI & SF & SI & SF & SI & SF \\
\hline Americana & 6.659 & $31,606,01$ & $1.786,52$ & 0,811 & 6,4 & 5,4 & 6,1 & 5,6 & 6,5 & 5,7 \\
\hline Cajuru & 285 & $12,241,74$ & $1.325,78$ & 0,71 & 8,6 & 6,1 & 7,2 & 5,4 & 6,0 & 4,9 \\
\hline S.C.do Sul & 11.009 & $73,796,33$ & $2.223,64$ & 0,862 & 5,9 & 5,2 & 6,4 & 5,2 & 6,6 & 5,3 \\
\hline
\end{tabular}

Fonte: Elaborado pelos autores com base em IBGE; Seade; MEC; Inep; Ideb.

Legenda: SI: séries iniciais; SF: séries finais. 
Detentora dos melhores resultados nas séries iniciais e finais no ano 2009, e com queda significativa nos índices em 2013, foram realizadas pesquisas no município de Cajuru na Secretaria Municipal de Educação para averiguar os motivos. As pesquisas indicaram:

- Mudança no modelo de gestão;

- Mudança no foco do ensino: adoção de projeto político pedagógico que envolve também a realidade sociocultural e econômica do entorno escolar (muitas famílias que migravam para trabalhar nas safras e entressafras de cana de açúcar, agora sem emprego e permanecem na cidade);

- Necessidade de melhoria e mais investimentos na merenda escolar;

- Necessidade de maior integração família-escola;

- Menor integração entre escola e Secretaria de Ensino e Planejamento Econômico;

- Queda na motivação dos docentes;

- Mudança no sistema de apostilamento.

\subsection{Contextos históricos municipais}

Em sua origem, Americana está ligada à imigração norte-americana para o Brasil na segunda metade do século XIX. Os primeiros registros dessa imigração datam de 1866, quando o coronel William H. Norris, também advogado e senador (Alabama) liderou o movimento de imigração trazendo consigo profissionais liberais, fazendeiros com experiência em agricultura, médicos, professores, dentistas. Quatrocentas famílias ocuparam uma área de quatrocentos quilômetros na região, constituindo quatro núcleos de povoamento (Estação, Retiro, Campo e Funil) que vieram a denominar-se de dimensão civilizatória norte-americana (RIBEIRO, 2008). Americana foi um polo irradiador da educação, estando esse setor vinculado a importantes personagens que contribuíram para o seu desenvolvimento no estado de São Paulo.

São Caetano do Sul foi um dos municípios que recebeu os imigrantes de Treviso, região do Vêneto, também na segunda metade do século XIX. Os colonos que lá se instalaram dedicaram-se ao cultivo de batata inglesa e da uva, para vinho de mesa. Essa última cultura não prosperou devido à praga que devassou todos os vinhedos (filoxera). Empobrecidos, os colonos venderam suas terras para as indústrias que começavam a se instalar naquelas localidades, mudando assim a configuração laboral.

Cajuru situa-se em região cuja formação histórica vinculou-se ao café. Nessa região, o trabalho no campo nas fazendas também esteve a cargo de colonos europeus desde fins do século XIX, como predominância de italianos. Na segunda metade do século $X X$, intensificou-se o assalariamento no campo e enfraquecendo consequentemente o antigo regime do colonato. Mais recentemente, o crescimento da área de cultivo da cana de açúcar, entre outras culturas, deu novo impulso à economia do município que permanece ligado à atividade agroindustrial.

Quadro 1 - Dimensões históricas, territoriais, econômicas e sociais

\begin{tabular}{|c|c|c|}
\hline Município & Território, população, economia & Educação \\
\hline Americana & $\begin{array}{l}\text { 133,63 km², } 213.493 \text { hab., 1.597,12 hab./km², } \\
\text { Conurbação alta. Desenvolvimento econômico } \\
\text { impulsionado pela imigração alemã e norte- } \\
\text { americana. Torna-se o pulsar têxtil do país. Após } \\
\text { a crise de 1990, realinha seu setor produtivo, } \\
\text { ampliando e diversificando seu parque industrial. }\end{array}$ & $\begin{array}{c}\text { Impacto da cultura norte-americana e dos missionários } \\
\text { presbiterianos (educação e desenvolvimento relacionados } \\
\text { às iniciativas na oferta de cursos técnicos). Imigrantes e } \\
\text { seus filhos são alfabetizados. Implantação de CIEPs (escola } \\
\text { tempo integral). Baixa aceitação inicial pela comunidade. } \\
\text { Rotulada de "escola para pobres". }\end{array}$ \\
\hline
\end{tabular}


Quadro 1 - Continuação

\begin{tabular}{|c|c|c|}
\hline Município & Território, população, economia & Educação \\
\hline Cajuru & $\begin{array}{c}\text { 660,69 km², } 23.624 \text { hab., 35,76 hab./km². } \\
\text { Agropecuária, café, cana de açúcar, arroz, } \\
\text { milho, feijão e soja e plantação de eucalipto. } \\
\text { Desenvolvimento industrial incipiente. }\end{array}$ & $\begin{array}{l}\text { Direcionou todos os esforços para um ensino de } \\
\text { qualidade: infantil e fundamental. Poder Executivo local } \\
\text { não conseguiu viabilizar a abertura de uma escola técnica. } \\
\text { (Município não tem mais de } 30 \text { mil habitantes). Intenso } \\
\text { envolvimento educação/comunidade. Discurso dos } \\
\text { gestores: a alteração das condições materiais passa por } \\
\text { uma boa educação. }\end{array}$ \\
\hline
\end{tabular}

Fonte: Elaborado pelos autores com base em IBGE; Seade; Secretarias de Planejamento, Educação dos Municípios.

\subsection{Desempenho educacional}

O município de Americana apresenta um índice baixo de municipalização do ensino para as séries iniciais do Ensino Fundamental comparativamente aos outros dois municípios. Tal resultado relaciona-se a uma concepção política de convivência com dois sistemas de ensino dentro de uma mesma rede: escolas de tempo integral e parcial (4h30).

Cajuru tem $100 \%$ de sua rede de ensino municipalizada. Americana e São Caetano do Sul, ainda dividem o Ensino Fundamental com escolas do Estado (INSTITUTO NACIONAL DE PESQUISAS EDUCACIONAIS ANÍSIO TEIXEIRA, 2007, 2009, 2011). Como dado adicional, informa-se que São Caetano do Sul possui uma bem desenvolvida política educacional de inclusão. Cajuru estabeleceu parcerias com outros municípios para a oferta do Ensino Médio profissionalizante.

A Tabela 3 apresenta os melhores desempenhos das escolas públicas dos municípios estudados no Ideb nos anos 2007, 2009 e 2011, bem como sua posição nos rankings estaduais e do Brasil.

Tabela 3 - EducaCenso - Ideb

\begin{tabular}{|c|c|c|c|c|c|c|c|c|}
\hline Município & Escolas & Rede & $\begin{array}{c}\text { Ideb } 2007 \\
\text { SI }\end{array}$ & $\begin{array}{c}\text { Ideb } 2009 \\
\text { SI }\end{array}$ & $\begin{array}{c}\text { Ranking } \\
\text { São Paulo } \\
2009\end{array}$ & $\begin{array}{c}\text { Ranking } \\
\text { Brasil } \\
2009 \\
\end{array}$ & $\begin{array}{c}\text { Ideb } 2011 \\
\text { SI }\end{array}$ & $\begin{array}{c}\text { Ideb } 2013 \\
\text { S.I }\end{array}$ \\
\hline Cajuru & E. Draibe & MUN & 7,2 & 9,0 & $1^{a}$ & $1^{a}$ & 8,1 & 6,2 \\
\hline Cajuru & Rugieri & MUN & 7,9 & 8,8 & $2^{a}$ & $2^{a}$ & 6,7 & 5,9 \\
\hline Cajuru & AS Mouzart & MUN & 6,5 & 8,5 & $4^{a}$ & $5^{a}$ & 6,8 & 5,6 \\
\hline Cajuru & Januário B. & MUN & 6,5 & 8,3 & $5^{a}$ & $8^{a}$ & 7,4 & 5,8 \\
\hline Cajuru & J. O. Menta & MUN & 6,4 & 8,2 & $7^{a}$ & $11^{a}$ & 7,4 & 8,1 \\
\hline Americana & P. Freire & MUN & 6,4 & 7,3 & $23^{a}$ & $94^{a}$ & 7,2 & 7,5 \\
\hline AAmericana & $\begin{array}{l}\text { F. Florestan } \\
\text { Fernandes }\end{array}$ & MUN & 6,1 & 6,9 & $83^{a}$ & $323^{a}$ & 6.6 & 6,7 \\
\hline Americana $(*)$ & P. Magaly R & MUN & 5,6 & 6,9 & $83^{a}$ & $323^{a}$ & 6,9 & 6,6 \\
\hline Americana & Arlindo. Soares. N & EST & 4,9 & 6,5 & $247^{a}$ & $890^{a}$ & 5,9 & 5,8 \\
\hline Americana (*) & O. C. Borgi & MUN & 5,5 & 6,0 & $247^{a}$ & $890^{a}$ & 5,2 & 5,8 \\
\hline S. C. Sul & $\begin{array}{c}\text { Benedito. Paulo } \\
\text { AS }\end{array}$ & MUN & - & 6,5 & $247^{a}$ & $890^{\mathrm{a}}$ & 6,9 & 7,6 \\
\hline S. C. Sul & Leandro Klein & MUN & - & 6,4 & $324^{a}$ & $1436^{a}$ & 6,2 & 6,2 \\
\hline S.C. Sul & 28 Julho & MUN & - & 6,3 & $412^{a}$ & $1436^{a}$ & 6,8 & 7,0 \\
\hline
\end{tabular}


Tabela 3 - Continuação

\begin{tabular}{c|c|c|c|c|c|c|c|c}
\hline Município & Escolas & Rede & $\begin{array}{c}\text { Ideb 2007 } \\
\text { SI }\end{array}$ & $\begin{array}{c}\text { Ideb 2009 } \\
\text { SI }\end{array}$ & $\begin{array}{c}\text { Ranking } \\
\text { São Paulo } \\
\mathbf{2 0 0 9}\end{array}$ & $\begin{array}{c}\text { Ranking } \\
\text { Brasil } \\
\mathbf{2 0 0 9}\end{array}$ & $\begin{array}{c}\text { Ideb 2011 } \\
\text { SI }\end{array}$ & $\begin{array}{c}\text { Ideb 2013 } \\
\text { S.I }\end{array}$ \\
\hline S. C. Sul & E. B. Braido & MUN & - & 6,2 & $412^{a}$ & $1782^{a}$ & 6,3 & 6,4 \\
\hline S. C. Sul & S. Flaquer & MUN & - & 6,2 & $525^{a}$ & $1782^{a}$ & 5,9 & 6,4 \\
\hline S.C. Sul & AR Pelegrino & MUN & - & 6,0 & $525^{a}$ & $2714^{a}$ & 6,6 & 6,7 \\
\hline
\end{tabular}

Fonte: Elaboração dos autores com base em MEC; Inep; Ideb (2007, 2009, 2011, 2013).

Nota: (*) Escola de Tempo Integral. Em 2007, segundo o MEC, São Caetano do Sul não teve número de participantes na Prova Brasil para que os resultados fossem divulgados.

A primeira observação refere-se à posição ocupada pelas escolas dos municípios no ranking estadual e nacional. As escolas de Cajuru obtiveram em 2009 as melhores avaliações do Brasil. Da mesma forma, seis dos sete maiores índices do Estado de São Paulo eram de escolas de Cajuru, assim como dos 11 maiores em todo o País.

Em Americana, no ano 2009, a escola que apresentou o melhor desempenho esteve na $23^{\mathrm{a}}$ posição. Em São Caetano, ainda em 2009, a escola com maior pontuação esteve em $324^{\circ}$ lugar. Enquanto os Idebs das escolas de Cajuru encontravam-se agrupados nas primeiras posições nos rankings estadual e nacional, as escolas de Americana e São Caetano do Sul demonstram maior dispersão de posicionamento. As últimas posições no ranking estadual e nacional de 2009 são: Cajuru, $7^{\mathrm{a}}$ e $11^{\mathrm{a}}$ posições; São Caetano do Sul, 2.952 a $9.698^{a}$, e Americana, 3.642 e $12.187^{a}$.

$\mathrm{Na}$ avaliação efetuada em 2011 esse quadro se altera. A escola melhor classificada de Cajuru obteve 8,1 (9,0 no ano 2009), ficando em 2011 na $13^{a}$ colocação. A escola mais bem posicionada no ranking nacional foi do município de Itaú de Minas (MG) com 8,6. Ou seja, os resultados de forma geral estiveram abaixo do ano 2009. O município de São Caetano do Sul apresentou sensível melhora no desempenho escolar.

A segunda observação refere-se à avaliação do Ideb das escolas dos municípios estudados relativa ao nível do desenvolvimento econômico do entorno escolar. Destaca-se que as escolas de Cajuru, com os Idebs mais elevados do estado e do Brasil, apresentam alto índice paulista de vulnerabilidade social (IPVS). A escola melhor colocada em 2009 e 2011 está situada em uma área cujo entorno o IPVS registra 5/6. O IPVS foi criado pela Fundação Seade no ano 2000. É composto de duas dimensões: socioeconômica e demográfica, e tem um sistema de indicadores que visa expressar o grau de desenvolvimento social e econômico dos municípios paulistas em seis grupos de vulnerabilidade social.

Os dados coletados são instigantes. É importante constar que em função dos diferentes portes e características dos municípios estudados, suas respectivas redes escolares têm também diferentes portes. O agrupamento dos índices de desempenho nos rankings nacionais sugere que, por trás do bom desempenho do município nos anos 2007, 2009 e 2011, existia uma condução homogênea da política educacional integrada à gestão executiva do município.

A nova Gestão Executiva priorizou itens como alimentação escolar, e substituiu o método de ensino apostilado buscando desempenho uniforme em todas as escolas. O declínio que já vinha sido observado no rendimento escolar em 2011, acentuou-se em 2013, com exceção a uma unidade escolar Jardim Onélia Menta, que manteve o bom desempenho. Mesmo considerando o declínio nos resultados gerais o desempenho das escolas do município esteve proporcionalmente acima da média de Americana e de São Caetano do Sul. 
No município de Americana, em 2010, a educação teve uma gestão voltada para o desenvolvimento humano na educação, uma política de oportunidades iguais, vários programas motivacionais e participação mais intensiva dos professores da rede em formação continuada, assim como desenvolvimento de propostas de integração escola-comunidade. Esse modelo de gestão participativa refletiu nos resultados dos índices de desempenho escolar. Uma ruptura de gestão ocorreu no primeiro semestre de 2011, cessando os programas implantados.

Nas pesquisas de campo realizadas nesses dois municípios, foram entrevistados gestores, professores, funcionários da Secretaria de Educação, bem como realizado um levantamento documental.

As entrevistas de campo tiveram por objetivo levantar as hipóteses para justificar esses resultados. Neste estudo são apresentadas sínteses dos depoimentos, dados os limites exíguos do artigo. Assim, adotou-se a metodologia de reproduzir os discursos mais comuns dos entrevistados, apresentando uma visão personalizada, mas, ao mesmo tempo, aquela mais próxima do pensamento coletivo.

No que se refere ao município de Cajuru, as informações recolhidas sinalizam uma forte ênfase da gestão na manutenção do compromisso entre diretores, professores e demais educadores envolvidos no dia a dia do ensino. Além disso, constatou-se como prática, uma atenção e abordagem pedagógica individualizadas com o alunado. Por outro lado, há uso do sistema de apostilamento como metodologia igualitária. Periodicamente uma avaliação do desenvolvimento do alunado é realizada por um supervisor externo à rede e à municipalidade.

O envolvimento da comunidade e a participação dos pais foram obtidos por meio da convocação e acompanhamento individual em casos de faltas ou baixo desempenho sistemático dos alunos. Constatou-se que as escolas classificadas nos primeiros lugares dos rankings situam-se em regiões com alto índice de vulnerabilidade social. A gestão adotou sistemas de comunicação geral com a comunidade, unidade volante, com alto-falante, chamando a atenção para os principais eventos educacionais, e reforçando a necessidade de um maior envolvimento dos pais/cuidadores.

Saindo de um baixo absenteísmo, que não é preocupante em Cajuru, chega-se a um índice de 12,5\% (2009) no município de Americana, que segundo as pesquisas realizadas com os educadores, são "fruto do stress a que são submetidos", " trabalham muito, têm salários baixos, e muitas vezes não se recebe apoio da família no ato de educar" (informação verbal). Destacaram-se também falhas no planejamento. Escolas de tempo integral contratam professores em tempo parcial, o que dificulta a formação da grade.

As entrevistas em São Caetano do Sul ficaram prejudicadas, pois foi a última cidade pesquisada. Isso ocorreu em 2012, e pode ser atribuído à proximidade do período eleitoral. Todavia, mesmo após esse período não houve boa receptividade do Executivo para responder às pesquisas. As informações foram obtidas no site oficial, antes de julho de 2012, e com os pais de alunos nas proximidades das escolas. Apesar das dificuldades de obtenção de dados, as pesquisas exploratórias indicaram ser São Caetano do Sul uma cidade inclusiva: Vários municípios a visitam no intuito de conhecer seus programas de acolhimento às desigualdades, pois ela erradicou o analfabetismo em seu território e há uma universidade municipal que incentiva, como uma das linhas de pesquisa, o desenvolvimento regional. Desenvolveu-se uma cultura externa de qualidade da educação, alicerçada pela presença de universidade municipal, entretanto esse fato carrega indícios de "despreocupação" dos pais quanto à qualidade do ensino oferecida nas escolas municipais. Em entrevista com um dos pais sobre sua percepção da qualidade do ensino de seus filhos, a resposta foi: "Ótima, pois está muito próxima a 6,0. Este é o limite, não é?" (informação verbal), 
demonstrando que o sistema de metas educacionais não é claro para os cidadãos.

No município de Americana, a percepção dos gestores voltou-se para as dificuldades administrativas. Dada a dimensão da rede, um dos obstáculos a serem superados é morosidade nos processos, por exemplo, as licitações. Para os gestores, a gestão escolar envolve diferentes aspectos como segurança, alimentação, transporte dos alunos, além dos processos pedagógicos propriamente ditos. Ainda na questão administrativa, notou-se entre os gestores grande preocupação quanto à valorização dos professores a partir de sua remuneração.

\section{CONSIDERAÇÕES FINAIS}

Pelos quadros referenciais apresentados, há evidências de que a melhoria da qualidade do ensino está mais relacionada à gestão, ao comprometimento, à responsabilidade, à formação e à avaliação do que ao volume de recursos aplicados. Às melhorias das condições salariais dos educadores deve-se acrescentar um conjunto de medidas e estruturais, de gestão, saindo do difuso compromisso dos discursos políticos. Observou-se também uma alta sensibilidade dos educadores com relação às mudanças, principalmente as decorrentes de processos eleitorais e da gestão executiva do município.

Os resultados do Ideb 2007/2009/2011/2013 permitem inúmeros cruzamentos analíticos, incluindo, por exemplo, maiores informações sobre a eficácia das instituições de ensino tempo integral. As escolas de tempo integral pesquisadas apresentam resultados abaixo das escolas de tempo parcial. Apesar de possuírem estruturas para acolher crianças para um longo período faltam-lhes adaptações físicas, operacionais e de recursos humanos para dar conta do atendimento de seu propósito. As grades horárias são mal articuladas, e os "buracos" preenchidos com atividades recreacionais disruptivas nas atividades do ensino.
Analisando os resultados do Ideb, constata-se que o município de Cajuru com baixo nível de riqueza e nível intermediário de longevidade e escolaridade (classificação 4 pela Fundação Seade) esteve no topo do ranking de desempenho escolar do Brasil e do Estado de São Paulo nos anos 2007, 2009, 2011. Mesmo com a queda no desempenho escolar, em 2013, ocasionado pela disrupção do Executivo e, consequentemente de suas prioridades, Cajuru mantém resultados comparáveis aos de Americana e de São Caetano do Sul, ambos com classificação 1 (elevado nível de riqueza e bons níveis de indicadores sociais), observando não existir correlação entre riqueza e disponibilidade para aprendizagem.

Tomou-se nesse estudo como referência, as séries iniciais buscando analisar a prontidão do alunado para a aprendizagem, independentemente de sua condição socioeconômica e também por duas localidades não absorverem totalmente o Ensino Fundamental, compartilhando-o com o Estado. Tal corte de estudo, entretanto, não foi prejudicial, mas revelou a maior atenção dos pais com as crianças nessa faixa etária, são indicadores de melhores resultados educacionais.

No município de Americana, ainda não ocorreu a total municipalização do Ensino Fundamental. Para o exemplo que se segue, tomou-se uma escola estadual, com séries finais e uma escola municipal, com séries finais: o entorno escolar de uma escola estadual do município de Americana, situado na região central, com elevado índice de riqueza do seu entorno (1), Escola Estadual Heitor Penteado (não oferece séries iniciais do Ensino Fundamental), apresenta resultados similares ao da Escola Municipal Florestan Fernandes, classificação 3 (entorno escolar vulnerável). Quanto aos resultados de São Caetano do Sul, as escolas públicas não apresentam fortes oscilações como os demais.

Na leitura e avaliação de um fato social, concreto, a partir do qual parâmetros são estabelecidos pelo EducaCenso é de relevante contribuição 
para intervenções específicas em contraposição ou justaposição com índices de desenvolvimento social e econômico, visando jogar algumas luzes às teorias que atribuem aos problemas econômicos e sociais todas as mazelas pelo desempenho escolar.

Este estudo apresenta indícios de que tal fato, considerado importante, tem outros elementos correlacionais para uma educação de qualidade a exemplo de:

- Como a educação se articula com as diferentes dimensões e espaços do entorno escolar;

- O comprometimento e ações do Poder Executivo local e da gestão escolar no cumprimento das metas educacionais estabelecidas;

- As diferentes modalidades de estruturas de ofertas de ensino (escola de tempo integral e parcial) que não contemplaram aumento efetivo do quadro e reorganização da grade escolar;

- As condições de trabalho e práticas políticas e elementos presentes na cultura institucional (organizacional) que impactam na motivação e absenteísmo;

- Modelos de gestão.

Os resultados da educação correlacionam-se com a qualidade da relação humana, profissional e política das localidades e o ambiente de trabalho - e relacionam-se diretamente com a qualidade dos insumos disponibilizados ao gestor da escola (desde seu aperfeiçoamento em técnicas gerenciais), aos educadores (formação continuada e relações intrapessoais) e o comprometimento da comunidade local.

Trata-se de um fenômeno complexo, abrangente, que envolve múltiplas dimensões, não podendo ser apreendido apenas pelo reconhecimento de algumas de suas variáveis, a exemplo de propostas ou discursos pedagógicos recorrentes nas práticas de ensino.

Observa-se que modelos de gestão educacional de resultados são perpassados pela gestão do capital humano, e não diferem das boas práticas administrativas, tal como ocorre nas empresas privadas. Motivação, valorização, metas e desafios, criatividade, preparo técnico, ambiente e clima organizacional são aspectos que afetam diretamente os resultados do ensino.

A qualidade do ensino é, pois, mediada por inúmeras dimensões que devem ser abordadas a partir de várias perspectivas. Todavia elas têm um fio condutor comum: o ensino-aprendizagem, sem colocar o foco apenas nas condições socioeconômicas do educando, ou de aprendizado em tempo integral para uma educação de qualidade.

Os resultados dos estudos são indicadores de que as avaliações das políticas sociais da localidade precisam de constância e monitoramento para as portas de entrada para a inclusão social e não apresentem obstáculos aos ingressantes, ou fechem suas portas de saída para a continuidade de estudos posteriores de seus egressos.

\section{REFERÊNCIAS}

ABBAGNANO, N. Dicionário de filosofia. 4. ed. São Paulo: Martins Fontes, 2000.

ARISTÓTELES. Política. 2. ed. Brasília: UNB, 1988.

AURELIANO, L.; DRAIBE, S. M. A especificidade do welfare state brasileiro. A política social em tempo de crise: articulação institucional e descentralização. Economia e desenvolvimento. v. I. Brasília, DF: CEPAL, 1989.

BAILLY, M. A. Abrégé du dictionnaire grec-français. Paris: Hachette, 1969. 


\section{REFERÊNCIAS}

BARCENA, A. et al. (Coords.). A hora da igualdade: brechas por fechar, caminhos para abrir. Brasília, DF: CEPAL, 2010.

BIRKLAND, T. A. An introduction to the policy process: theories, concepts, and models of public policy. Cambridge: Cambridge University, 2003.

BOURDIEU, P. Questões de sociologia. Rio de Janeiro: Marco Zero, 1983.

BRASIL. Constituição (1988). Constituição da República Federativa do Brasil: promulgada em 5 de outubro de 1988. 4. ed. São Paulo: Saraiva, 1990. 168 p. (Série Legislação Brasileira).

Ministério da Educação. Portaria Ministerial $n^{\circ}$ 489, de 18 de março de 1993. Institui o Plano Decenal de Educação para Todos. Brasília: MEC, 1993.

Lei $n^{\circ}$ 9394, de 20 de dezembro de 1996. Brasília: Ministério da Educação, 1996.

Lei no 10.172, de 9 de janeiro de 2001. Aprova o Plano Nacional de Educação 2001-2010. Diário Oficial da União, Brasília, 10 jan. 2001.

Indicações para subsidiar a construção do Plano Nacional de Educação 2011-2020: Comissão Bicameral para Estudo do Plano Nacional Educação (2011-2022). Brasília: Ministério da Educação, 2009.

BRESSER, P. L. C. A reforma do estado dos anos 90: lógica e mecanismos de controle. Brasília: Ministério da Administração Federal e Reforma do Estado, 1997.

CAllegari, C. (Org.). O Fundeb. 4. ed. São Paulo: Aquariana, 2009.

CALMON, P. História social do Brasil. 2. ed. São Paulo: Martins Fontes, 2002. v. III.
COMTE, A. Curso de filosofia positivista/discurso preliminar sobre o conjunto do positivismo/ catecismo positivista. São Paulo: Nova Cultural, 1988. (Coleção Os Pensadores).

COROMINAS, J.; PASCUAL, J. A. Diccionario crítico etimológico. Madrid: Gredos, 1985.

DAWSEY, J. C. (Org.). Americanos, imigrantes do velho sul no Brasil. Piracicaba: UNIMEP, 2005.

DEWEY, J. Vida e educação. São Paulo: Melhoramentos, 1971.

DRAIBE, S. M. Avaliação de implementação: esboço de uma metodologia de trabalho em políticas públicas. In: BARREIRA, M. C.; CARVALHO, M. C. B. (Orgs.). Tendência e perspectivas na avaliação de políticas e programas sociais. São Paulo: IEE; PUC SP, 2001.

FÁVERO, O. (Org.). A educação nas constituintes brasileiras, 1823-1988. Campinas: A. Associados, 1996.

FURTADO, C. A formação econômica do Brasil. 34. ed. São Paulo: Cia das Letras, 2007.

GIL, A. C. Métodos e técnicas de pesquisa social. São Paulo: Atlas, 2001.

HEIDEMANN, F. G. Do sonho do progresso às políticas de desenvolvimento. In: HEIDEMANN, F. G.; SALM, J. F. (Orgs.). Políticas públicas e desenvolvimento: bases epistemológicas e modelos de análises. Brasília: UnB, 2009.

HEFLINGER JR, J. E. Ibicaba, o berço da imigração europeia de cunho particular. Limeira: Unigráfica, 2007.

HOUAISS, A.; SALLES M. Dicionário Houaiss da língua portuguesa. Rio de Janeiro: Objetiva, 2001. 


\section{REFERÊNCIAS}

INSTITUTO BRASILEIRO DE GEOGRAFIA E ESTATÍSTICA. Anuário estatístico do Brasil, 2010. v. 70. Rio de Janeiro: IBGE, 2010.

INSTITUTO NACIONAL DE PESQUISAS EDUCACIONAIS ANÍSIO TEIXEIRA. Censo educacional, 2007/2009/2011/2013. Brasília: Ministério da Educação, 2013.

JACOBUCCI, A. M. Revolucionou e acabou? Breve etnografia do Ginásio Estadual Vocacional de Americana - GEVA. São Carlos: Compacta, 2002.

KUENZER A. Z. A pedagogia da fábrica: as relações de produção e educação do trabalhador. São Paulo: Cortez, 1985.

LANDAU, S. I. et al. Chambers English dictionary. Cambridge: Cambridge University, 1988.

LÉVI-STRAUSS, C. Introdução à obra de Marcel Mauss. v. 2. São Paulo: EDUSP, 1974.

LIDDELL, H. G.; SCOTT, R. A greek-english lexicon. Oxford: Claredon, 1968.
MARTINS, P. H. A sociologia de Marcel Mauss. Dádiva, simbolismo e associação. Revista Crítica de Ciências Sociais, n. 73, dez. 2005.

PERRY, A. O fim da história: de Hegel a Fukuyama. Rio de Janeiro: Zahar, 1992.

RIBEIRO, D. O livro dos CIEPs. Rio de Janeiro: Bloch, 1986.

RIBEIRO, M. J. V. (Org.). Descobrindo americana: um grande salto. Prefeitura Municipal de Americana, 2008.

SAVIANI, D. Da nova $L D B$ ao Fundeb: por uma outra política educacional. 2. ed. Campinas, SP: Autores Associados, 2008.

SCHWARTZMAN, S.; COX, C. Políticas educacionais e coesão social: uma agenda latino-americana. São Paulo: iFHC, 2009.

STOCK, S. V. Entre a paixão e a rejeição: quadro histórico-social dos CIEPs. Americana: Adonis, 2004.

SWAN, M. Practical english usage. 3. ed. Oxford: Oxford, 2000. 